Indonesian Journal of Biotechnology, June, 2013

Vol. 18, No. 1, pp.52-57

\title{
Cloning and Expression of hGAD65 Gene in E. Coli BL21
}

\author{
Rista Nikmatu Rohmah', Soraya Widyasari ${ }^{1}$, Aulanni' $^{1}{ }^{2}$, and Fatchiyah ${ }^{1}$ \\ ${ }^{1}$ Departement of Biology, Faculty of Mathematic and Natural Science, Universitas Brawijaya, Malang, \\ Indonesia \\ ${ }^{2}$ Departement of Chemistry, Faculty of Mathematic and Natural Science, Universitas Brawijaya,Malang, \\ Indonesia
}

\begin{abstract}
The aim of this study is to construct the $h$ GAD 65 gene and to identify the $h$ GAD 65 clone by using PCR \& RFLP. The samples were derived from normal person \& DM patient's blood. Blood DNA was isolated by salting out method and then amplified by PCR with a pair of specific primer, GAD65-F-BamH1-807 \& GAD65-R-Xho1945. The PCR-product was cloned into vector pET-28a and the pET28a-hGAD65-clone was transformed into E.coli BL21 competent cells. The pET28a-hGAD65-clone was confirmed by PCR and RFLP by BamH1 \& XhoI. The PCR product of pET28a-hGAD65-clone was one band of $159 \mathrm{bp}$ and has two bands $5.3 \mathrm{~kb}$ and $159 \mathrm{bp}$ by RFLP with both restriction enzymes. The GAD65 protein is expressed in 65kD of pET28a-hGAD65-clone. PET28ahGAD65-clone was able to recognize by gold standard monoclonal antibody specifically. These results indicated that the $h$ GAD 65 gene inserted into pET28a properly and provided the GAD65 protein expression.
\end{abstract}

Key words: hGAD65, PCR, pET-28a, RFLP

\section{Introduction}

Type 1 diabetes mellitus (DM) is an autoimmune disease characterized by destruction of the beta cells of pancreas. This type of diabetes decrease insulin production that cause an increase of glucose within the blood stream (Lukiati et al., 2012). According to WHO data, Indonesia is the fourth country with the largest number of diabetes individuals after China, India, and America. The number of people with type 1 diabetes in Indonesia is estimated total of 5\% - 10\% of the overall number of diabetics (Asril and Yuniarti, 2012). Type 1 DM commonly occurs in childhood, adolescence and manifested in adult. Markers of autoimmune of the type 1 diabetes are Inset Cell Antibodies (ICA), Insulin Auto-Antibodies (IAA) and Anti-

*Corresponding author :

Fatchiyah

Department of Biology, Faculty of Mathematic and Natural Science, Universitas Brawijaya Jl. Veteran, Malang, 65145, Indonesia, Telp/Fax: 0341-575841, E-mail: fatchiya@ub.ac.id
Glutamic Acid Decarboxylase (anti-GAD65). Patients of type $1 \mathrm{DM}$ are present in $85 \%$ of Anti-Glutamic Acid Decarboxylase (antiGAD65) in the beta cells of pancreas (Truyen et al., 2007).

The previous research reported that antiGAD65 autoantibodies were explored from beta- pancreatic cells of bovine brain as earlier marker detection of type 1 DM (Soeatmadji et al., 2005). In this study, material used was $h G A D 65$ gene produced from bovine brain as original source. However, this original source had no equally quality and stability. To solve this problem, we constructed $h G A D 65$ gene into plasmid pET-28a that have same characteristic with original source and will be able to use as material to produce reagent diagnostic kit of type $1 \mathrm{DM}$.

\section{Materials and Methods \\ Preparation of DNA from human blood \\ Human blood samples derived from normal people as positive control and type 1 DM patients from Saeful Anwar}


Hospital Malang, coded 5.2jpp and 13.2 jpp of positive Type $1 \mathrm{DM}$ clinical-testing. Blood DNA was isolated by salting out method (Gaaib et al., 2011). Quality \& Quantity DNA were measured by using Nano Drop spectrophotometer and 1\% agarose gel electrophoresis.

\section{DNA amplification}

Blood DNA was amplified by primer GAD65-F-BamH1-807 \& GAD65-R-XhoI945.Our primer was designed specifically at partial exon 4 of $h G A D 65$ gene. PCR program: hot start $94^{\circ} \mathrm{C}$ for $1 \mathrm{~min}$, denaturation $94^{\circ} \mathrm{C}$ for $30 \mathrm{~s}$, annealing $57^{\circ} \mathrm{C}$ for $30 \mathrm{~s}$, and extension $72^{\circ} \mathrm{C}$ for $45 \mathrm{~s}$ (35 cycles), and then post extension $72^{\circ} \mathrm{C}$ for $7 \mathrm{~min}$. PCR products were measured qualitatively by using $2 \%$ agarose gel electrophoresis. PCR products were sequenced by same primer to identified hGAD 65 gene.

\section{Preparation of DNA vector}

Plasmid pET-28a was transformed into E.coli strain BL21 competent cells (Novagen) \& cultured the clone in LB agar medium containing antibiotics kanamycin and chloramphenicol antibiotics. DNA plasmid was isolated by miniprep method ( Birnboim and Doly, 1979). The quality \&quantity of DNA plasmids were measured by using Nano Drop spectrophotometer and $1 \%$ agarose gel electrophoresis.

\section{Gene cloning of hGAD65 gene into plasmid pET-28a}

DNA plasmid and PCR product were digested by BamHI and XhoI enzymes. After purification by elution method, between DNA pET28a-digested and hGAD65amplified gene target were ligated by T4-DNA ligase. The pET28a-hGAD65construction transformed into E. coli BL21 competent cells and cultured on LB-selected agar medium containing kanamycin and chloramphenicol antibiotics for blue white colony screening.

\section{Confirmation of the recombinant DNA by PCR and RFLP}

To confirm the recombinant DNA, white colonies were isolated by miniprep method. PCR analysis is using a pairs same GAD65 primer. RFLP analysis is using restriction enzymes BamHI and XhoI. PCR and RFLP products were measured qualitatively by using $2 \%$ agarose gel electrophoresis.

\section{Isolation, characterization and detection of recombinant protein from $h G A D 65$ clone by specific antibody}

White colony was cultured in LB agar medium containing kanamycin and chloramphenicol antibiotics. Protein was isolated from supernatant medium by Ward \& Swiatek method (Ward \& Swiatek, 2009). Protein bands were separated using electrophoresis and run by SDS-PAGE 10 $\%$. Detection of Recombinant protein by dot blot testing using specific primer antibody from type $1 \mathrm{DM}$ patient serum (Soeatmadji, et al., 2005) and Anti-Rabbit IgG labeled with Alkaline Phosphatase conjugated as secondary antibody. Positive control derived from standard protein of GAD65 ELISA kit and negative control using PBS NaN3 1\%. Density of GAD65 clone-anti hGAD65 reaction measured quantitatively by Quantity One program and analyzed by Microsoft Excel.

\section{Results}

Target gene of partial exon 4 of hGAD65 was $159 \mathrm{bp}$ (Figure 1A). The bands of $159 \mathrm{bp}$ of partial exon 4 hGAD65 was observed on normal person (Lane 3 and 4) and DM patient's blood (Lane 5 and 6). Figure 1B showed RFLP products of pET-28a and target gene hGAD65 of partial exon 4 . The result of alignment of sequencing product and gene sequence from gene bank showed that positive control (R1) have similarity with GAD65 sequence from gene bank at partial exon 4 (Figure 1C). However, sequence of 13.2jpp, control positive (S2) and 5.2jpp had a difference from GAD65 sequence of gene bank. 
Rohmah et al.

I.J. Biotech.

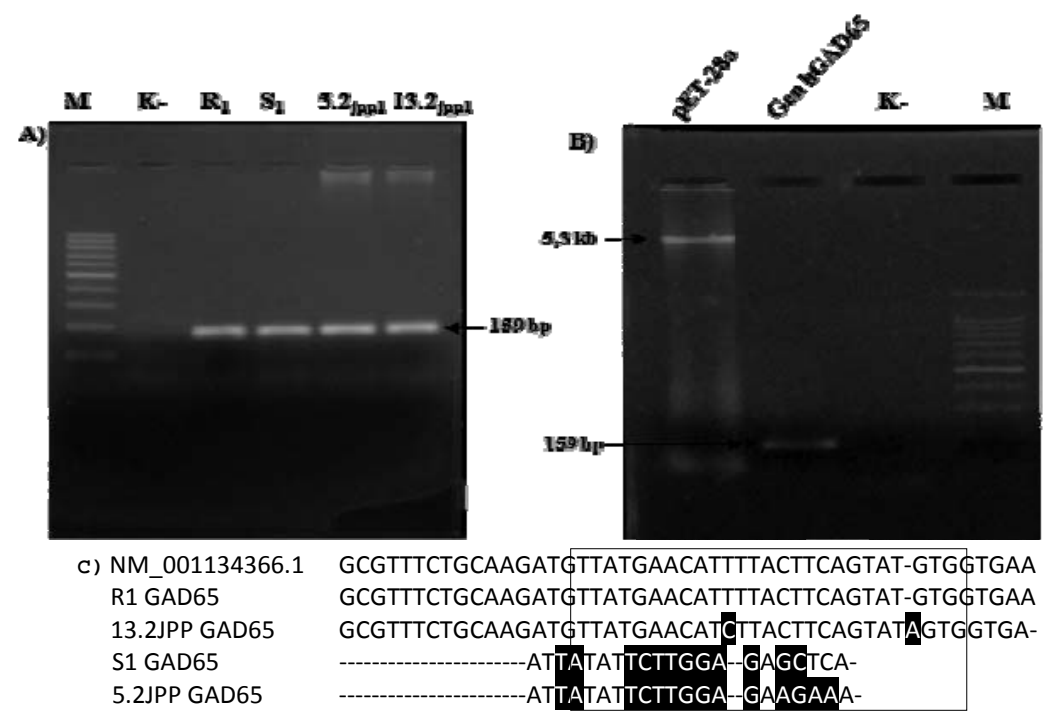

Figure 1. DNA target and vector preparation. PCR product of hGAD65gene (A). Plasmid pET-28a and PCR product was digested by restriction enzyme BamHI and XhoI (B). M: Marker; K-: Negative Control; $\mathrm{R}_{1}$ \& S: Normal Control; 5.2jpp and 13.2jpp are Type $1 \mathrm{DM}$ patients. Alignment of hGAD65 gene partial exon 4 from gene bank and sequencing product(C). NM_001134366.1 : GAD65 from gene bank, R1\&S1GAD65: Normal Control, 5.2jpp \& 13.2jpp GAD65 : type $1 \mathrm{DM}$ patients
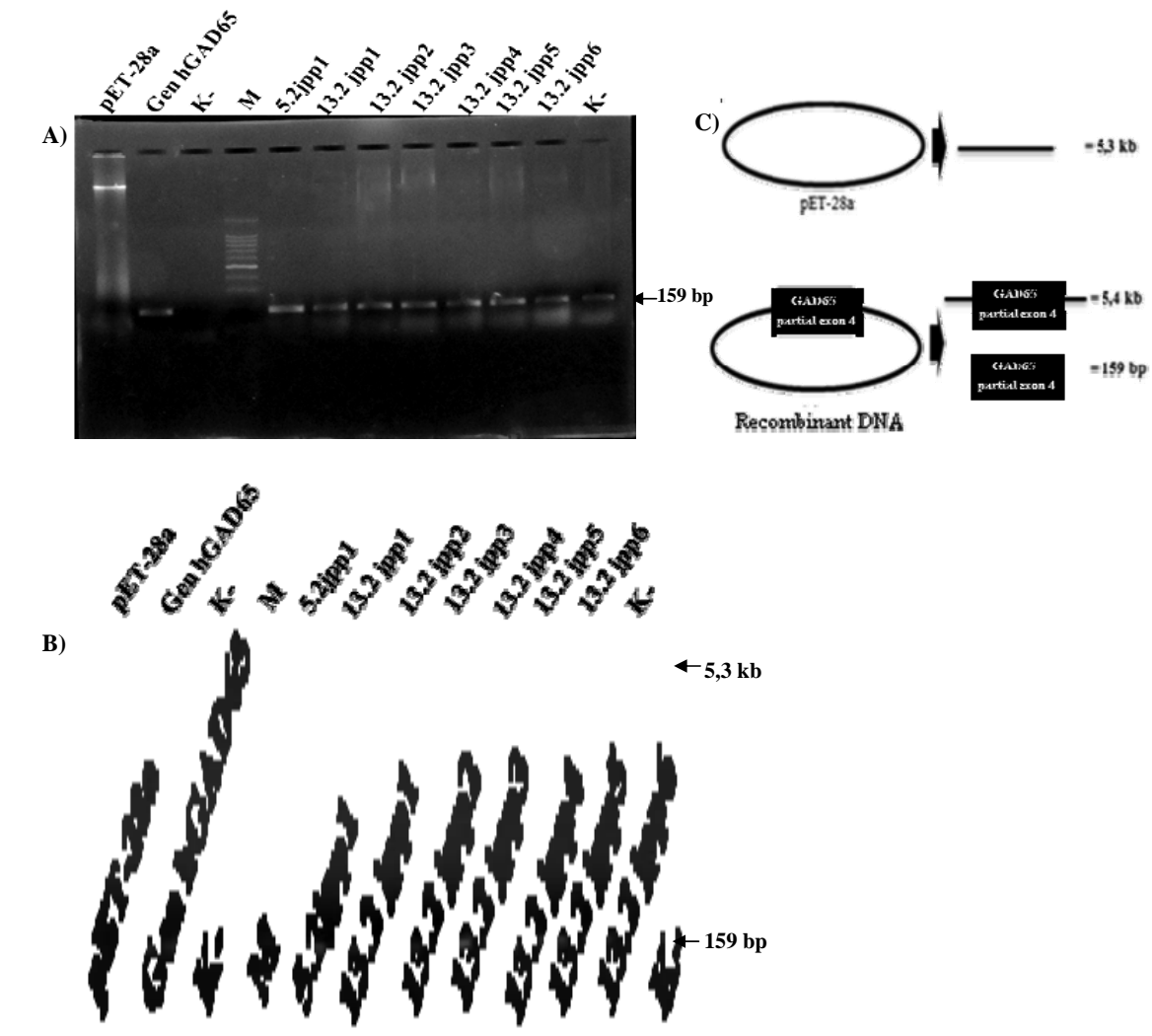

Figure 2. Selection of hGAD65 gene recombinant identified by specific GAD65 primer (A) and selected by BamHI and XhoI enzymes (B). Schematic of DNA pET-28a and hGAD65 gene recombinant.M: Marker; K-: Negative Control; R \& S: Normal Control; 5.2jpp and 13.2 jpp are Type 1 DM patients. 
(A)

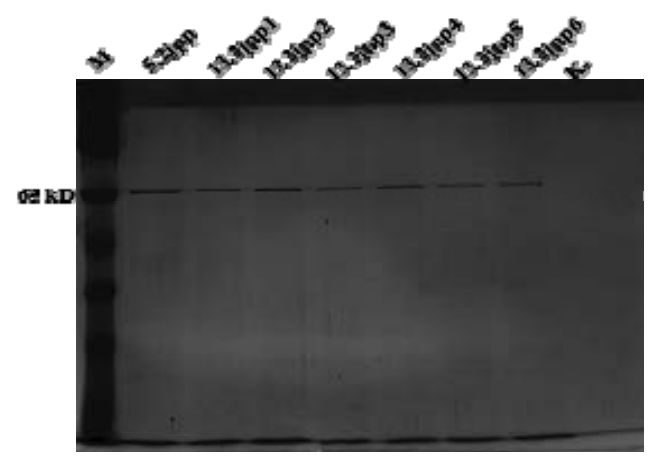

(C)

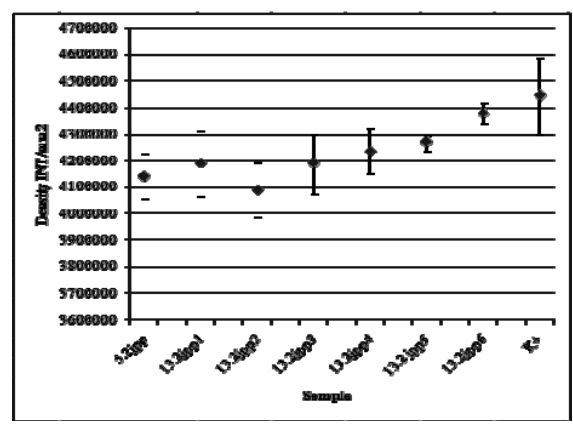

(B)

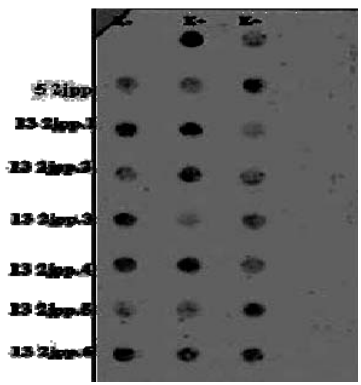

Figure 3. Detection of hGAD65 gene by SDS PAGE 10\% (A), and Detection by hGAD65 Antibody Spesific (B), Statistic Analysis of dot blot (C)

Identification of recombinant DNA with PCR amplification using a pair of GAD65-FBamH1-807 \& GAD65-R-Xho1-945 primer was shown in Figure 2A. We detected one band of $159 \mathrm{bp}$ to type $1 \mathrm{DM}$ patient and positive control from normal person. We also detected two bands of RFLP product (Figure 2B,lane 5-12) as well as the digestion schematic of two DNA band, $5.3 \mathrm{~kb}$ of plasmid \& $159 \mathrm{bp}$ as target gene (Figure $2 \mathrm{C}$ ).

The result of $h G A D 65$ characterization by SDS PAGE $10 \%$ showed protein band with molecule weight of $65 \mathrm{kD}$ (Figure $3 \mathrm{~A})$. The protein bands of $65 \mathrm{kD}$ was found on type $1 \mathrm{DM}$ patient's blood (Lane 2-8), whereas negative control did not show the protein band (Lane 9). Identification of recombinant proteins using specific antibody showed that blue-purple visualization on spots of positive control and recombinant proteins from type $1 \mathrm{DM}$ patients. Whereas, the negative control not showed the bluepurple visualization (Figure 3B). Binding of recombinant proteins and antibody specific was measured quantitatively by Quantity One showed that control positive was higher of mean density than type $1 \mathrm{DM}$ patient samples (Figure 3C).

\section{Discussion}

DNA band of 159bp was found all of samples, both in normal person and type 1 DM patient's blood. Why did we use the partial exon 4 of GAD65 gene? Previous experiments suggested that in partial exon 4 had two long amphiphilic helical regions of epitopes antibody. The epitope can be recognized to antibody by presenting of GAD65 peptide on T-cell. In diagnostics, $80 \%$ of type $1 \mathrm{DM}$ had antibody that recognize the GAD65 as autoantibody. The compatibility of partial exon 4 was proved by expressions of amino acid sequence. The region of GAD65 protein cloned located in N-terminal of exon 4 (Schwartz et al., 1999).

The PCR products of target gene $h$ GAD 65 of partial exon 4 can confirmed with alignment result show that to normal person 
(R1) have similarity from gene bank, whereas partial exon 4 of type $1 \mathrm{DM}$ patient, both of positive control (S1), 5.2jpp and 13.2jpp show mutation at nucleotide base that affect to acid amino structure. According to Matsukawa and Ueno (2007), the mutation of gene GAD65 can caused by exposure of peptide would require degradation of GAD65. We are expected that the mutation of positive control show that person have type 1 DM history.

The PCR products of $\mathrm{pET} 28 \mathrm{a}-\mathrm{hGAD65-}$ clone resulted in one band of 159bp indicated that a pairs GAD65-F-BamH1-807 and GAD65-R-Xho1-945 primers recognized target $h G A D 65$ gene specifically (Figure $2 \mathrm{~A}$ lane 5-12). This indicates that $h$ GAD 65 gene at partial exon 4 was inserted into plasmid pEt-28a properly. The good design of specific primers of target gene would provide excellent of DNA recombinant construction of specific gene (Tong, 2011). Negative control of pET-28a (Lane 1) did not produced amplified amplification of hGAD65 gene. Lane 12 was positive control which $159 \mathrm{bp}$ hGAD65 gene derived from blood of normal person. According to Matsukawa and Ueno (2007), GAD was widely distributed among living cells of various organisms from mammalians to single cell organisms. The previous study suggested that GAD65 was expressed on leucocytes from healthy individuals (Matsukawa and Ueno, 2007).

RFLP product resulted in two bands which suggesting the restriction enzyme recognizes sites of vector and target gene. According to Hsieh and Williams (2012), when the restriction site between the target DNA and the plasmid vector ligation have to made recombinant in within. To confirm the recombinant restriction site, we could cut the DNA recombinant by the same restriction enzyme.

Our result found the target protein expressed on $65 \mathrm{kD}$ (MW) proved that $h G A D 65$ gene partial exon 4 was inserted into plasmid pET-28a. According to Weber and Osborn (2006), SDS- PAGE can determine the molecular weight of proteins. Our previously study reported the GAD65 is an enzyme with molecular weight $65 \mathrm{kD}$ which as marker autoimmune for type 1 diabetes. In diagnostics some diabetes patients, $80 \%$ of type 1diabetes have antibody that can recognize the GAD65 (Soeatmadji et al., 2005).

Spots with blue-purple visualization on nitrocellulose membrane indicated that primer antibody and secondary antibody had positive reaction with recombinant protein from hGAD65 clone. Positive reaction showed that was successfully of labeling of pET28a-hGAD65-clone (Soeatmadji et al., 2005). According to Guillemin et al., (2009), dot-blot assay did not use separated protein according to their molecular weight, but protein could be expressed by the primary antibody.

The dot blot assay also showed color intensity to determine titer of antigenantibody binding. An antibody titer is used to measure of how much antibody that recognizes a particular epitope (Kogelnik, et al., 2006). Positive control that derived from standard protein of GAD65 ELISA kit was highest intensity among of all (Figure 3B). These result indicated that positive control had highest titer of antigen antibody binding. The thicker of dot blot color will determine that the higher of GAD concentration (Soeatmadji et al., 2005)

Titer antigen-antibody also was determined by density mean of product of pET28a-hGAD65-clone (Figure 3C). Positive control also showed highest mean. However, the mean of positive control and pET28a-hGAD65-clone product did not show significant mean, indicating that product of pET28a-hGAD65-clone can be used to material kit diagnostic type $1 \mathrm{DM}$ properly.

In this study, pET-28a- hGAD65 clone was inserted properly and GAD65 protein of clone was expressed as well. This result indicated that partial exon 4 of $h$ GAD 65 gene showed appropriate with hGAD65 protein sequence. 


\section{Acknowledgements}

Thank you to Prof. Wolfgang Nellen, Kassel University, German, for providing pET28 and E. coli BL21 competent cells, and this study was supported by Biosains Universitas Brawijaya and PT. Biofarma (Persero) for funding collaboration.

\section{References}

Asril, N.M. and Yuniarti, K.W., 2012. Experiencing and managing Type 1 diabetes mellitus for adolescents in Indonesia: An integrated phenomenology and indigenous psychological analysis. Intl. J. Res. Studies in Psychol., 1(2), 8195.

Birnboim, H.C., and J.Doly, 1979. A rapid alkaline extraction procedure for screening recombinant plasmid DNA. Nucleic Acids Res., 7(6), 1513-1523.

Gaaib, J.N., Nassief, A.F. and Al-assi, A.H., 2011. Simple salting - out method for genomic DNA extraction from whole blood Abstract: Introduction : Tikrit J.Pure Sci., 16(2), 15-17.

Guillemin, N., Meunier, B., Jurie, C., CassarMalek, I., Hocquette, J-F., Leveziel, H., Picard, B., 2009. Validation of a Dot-Blot quantitative technique for large scale analysis of beef tenderness biomarkers. J. Physiol. Pharmacol. 60 (10), 91-7.

Hsieh, A. and Williams, E., 2012. Genetic Compensation of E . coli C156 with pBAD-ompA for the Investigation of Conjugation Efficiency. J. Exp. Microbiol. Immunol.(JEMI), 16, 113-118.

Kogelnik, A.M., Loomis, K. and Hoeghpetersen, M., 2006. Use of valganciclovir in patients with elevated antibody titers against Human Herpesvirus-6 ( HHV-6) and Epstein - Barr Virus ( EBV) who were experiencing central nervous system dysfunction including long-standing fatigue. J. Clini. Vir., 1, S33-S38.

Lukiati, B., Aulanni' am and Darmanto, W., 2012. The Effects of Curcuma heyneana Ethanolic Extract on the Superoxide
Dismutase Activity and Histological Pancreas of Type 1 Diabetes Mellitus Rats. Intl. J.Basic App. Sci. (IJBAS-IJENS) 12 (2), 22-30.

Matsukawa, S and Ueno, $\mathrm{H}^{1} ., 2007$. Expression of Glutamate Decarboxylase Isoform, GAD65, in Human Mononuclear Leucocytes A Possible Implication of C-terminal End Deletion by Western Blot and RT-PCR Study. J.Biochem. 142(5), 633-638.

Matsukawa, $\mathrm{S}$ and Ueno, $\mathrm{H}^{2}$., 2007. Analysis of intron-exon positioning on glutamate decarboxylase and its relation with evolution. J. Biol. Macromol., 7(3), 35-48.

Schwartz, H.L., Chandonia, John.M., Kash, S.F., Kanaani, J., Tunnell, E., Domingo, A., Cohen, F.E., Banga, J P., Madec, Anne .M., Richter, W., 1999. High-resolution Autoreactive Epitope Mapping and Structural Modeling of the $65 \mathrm{kDa}$ Form of Human Glutamic Acid Decarboxylase. J. Mol. Biol., 287, 983-999.

Soeatmadji, D. W., Aulanni'am, Fatah, F., Sumitro, S.B., 2005. Detection of GAD65 autoantibodies of type-1 diabetes using anti-GAD65-abs reagent produced from bovine brain tissue. Med. J. Indo., 14(4), pp.197-203.

Tong, K., 2011. Construction of pBAD-clones using the TOPO TA Cloning System. J.Exp.Microbiol.Immunol. (JEMI), 15, 136-141.

Truyen, I., De Grijse, J., Weets, I., Kaufman, L., Pipeleers, L., Nanos, N., Decochez, K., Hilbrands, R., Kaufman, J-M., Keymeulen, B., Mathieu, C., Van Gaal, L., Pipeleers, D G., Gorus, F.K., 2007. Identification of prediabetes in first-degree relatives at intermediate risk of type I diabetes. J.Immunol.: Clin. Exp. Immunol., 149(2), 243-50.

Ward, W.W. and Swiatek, G., (2009). Protein Purification. Current Analytical Chemistry, 1-21.

Weber, K. and Osborn, M., 2006. SDS-PAGE to Determine the Molecular Weight of Proteins : the Work of Klaus Weber and 